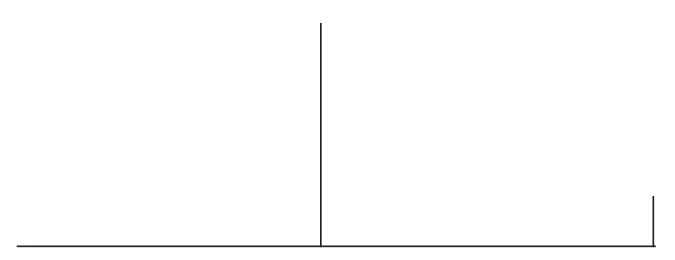

\title{
Psicossomática, uma "saída" fora da estrutura
}

\author{
Milton Lopes de Souza
}

A partir da experiência psicopatológica do atendimento a pacientes acometidos de patologias somáticas, o autor ensaia algumas elaborações acerca dos conceitos de estruturas psíquicas em psicanálise, no que tange às manifestações psicossomáticas. Propõe o psicossoma ou aparelho psicossomático, em oposição ao termo aparelho psíquico, numa tentativa de dar conta da complexidade e da unidade biopsicofísica que constitui o ser humano. 


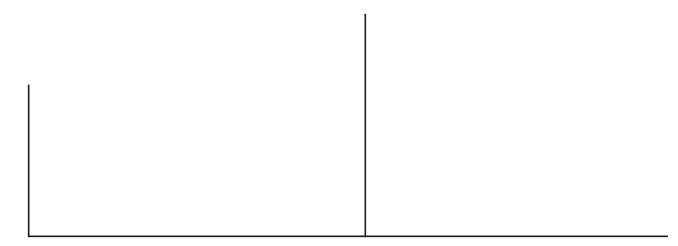

Atendimentos a pacientes com "saídas" psicossomáticas, termo que pretendo desenvolver ao longo deste texto, têm-me feito pensar algumas questões em psicopatologia e em psicanálise.

A escuta psicanalítica supõe um despojamento teórico e uma atenção flutuante, ausência de preconceitos e disponibilidade para vivenciar a aventura que o inconsciente propõe como atos de surpresa. Da mesma forma, a construção de um texto em psicopatologia nos convida a deixar-nos surpreender pela experiência clínica, permitindo que ela nos interrogue sobre a teoria.

É comum ouvirmos os psicanalistas zombarem da nosografia psiquiátrica, do DSM IV, da postura fenomenológica e descritiva. No entanto, a escuta psicanalítica pode ser permeada pelo mesmo congelamento, à medida que ouvimos com nosso imaginário a histeria deste paciente, a obsessão daquele e a perversão ou a psicose de outro.

A transferência pode se transformar em mortífera, histerogênica, psicótica e até psicossomatógena, a partir do momento em que o analista não possibilite um espaço de vazio ou de falta para o inconsciente dele e de seu analisando se manifestarem e poderem ser capturados num instante pontual, revelador de uma verdade.

Proponho esta breve introdução para pensar a psicossomática como uma "saída", no sentido de porta dos 
fundos, no sentido de uma out-structure, ou seja, ela interroga a noção de estruturas psíquicas como funcionamentos estanques.

Mesmo Lacan, estruturalista por excelência, situou os fenômenos psicossomáticos, enquanto lesões corporais, fora da estrutura neurótica; também não se trataria de uma nova estrutura, podendo ocorrer tanto em neuróticos, psicóticos ou perversos. Para Lacan, os fenômenos psicossomáticos marcam o corpo por estarem fora do campo da linguagem e, portanto, irredutíveis à intervenção da análise (Seminários 2, 3 e 11) 1,2,3. A articulação significante sofreria um black-out, e o gozo ou o fluxo pulsional inconsciente se manifestaria no corpo, na loucura celular, realizando a pulsão no mais genuíno gozo da dor.

A proposta lacaniana para a psicossomática se restringe aos fenômenos ou lesões corporais que comprometem a estrutura celular, relegando todas as demais participações do corpo, sejam as funcionais e fisiológicas, ou ao campo da histeria, ou como não interessando ao campo psicanalítico.

Joyce McDougall ${ }^{4}$ apresenta uma posição diferente. A partir de sua experiência clínica e apoiada em Winnicott e na Escola Psicossomática de Paris (P. Marty, Fain e M'Uzan), propõe que os acidentes de percurso que se originam desde a unidade mãe-bebê, onde as trocas são fundamentalmente de natureza sensorial e infraverbal, até a separação com a constituição e a apropriação da linguagem pelo psicossoma próprio da criança, podem introduzir, no funcionamento psicossomático, certos núcleos afetivos dissociados das representações. Estes afetos atualizados pelo encontro com situações conflitivas podem eludir respostas somáticas, que são maneiras arcaicas de respostas na criança.

Essa autora evoca a falha da imago paterna no trabalho de separação mãefilho, ficando esta imago relegada a figuras ameaçadoras ou insignificantes, conceito análogo ao de função paterna ou nome-do-pai em Lacan.

Minha tendência, a partir da clínica, é conceber o aparelho psíquico como um aparelho psicossomático (embora o termo aparelho seja muito mecânico), altamente dinâmico e funcionando como uma unidade. Este aparelho psicossomático, ou psicossoma, seria constituído pela bagagem genética, trabalhado pela história, pela linguagem e pelas experiências originadas a partir do corpo (pois sem ele não existiria o psiquismo), sobretudo nas vivências perinatais, primeiros anos de vida e finalmente pelo Édipo e pela sexuação.

1. J. Lacan. O seminário. Livro 2 - O ego na teoria de Freud. Rio de Janeiro, Jorge Zahar.

2. J. Lacan. O seminário. Livro 3 - As psicoses. Rio de Janeiro, Jorge Zahar.

3. J. Lacan. O seminário. Livro 11 - Os quatro conceitos fundamentais da psicanálise. Rio de Janeiro, Jorge Zahar.

4. J. McDougall. Teatros do corpo. São Paulo, Martins Fontes, 1996. 
$\begin{array}{lllllll}R & E & V & \text { I } & S & T & A\end{array}$

LATINOAMERICANA

DE PSICOPATOLOGIA

F U N D M N T A L

Este aparelho psicossomático não diz respeito ao corpo puramente biológico da medicina, porque trata-se do corpo de vivência, um corpo para o usufruto, um corpo que faz circular a pulsão, um corpo investido, erotizado, permeado pela psique, célula a célula, que existe para gozar. Entendemos aqui o conceito de gozo em Freud e em Lacan, no sentido da manifestação do inconsciente e do fluxo pulsional.

Freud, no "Projeto para uma psicologia científica"5 e em "Pulsão e seus destinos", nos remete aos caminhos da pulsão (Bahnungen), facilitações, antecipando inclusive as noções de sinapse e das vias facilitadoras e inibitórias da neurofisiologia.

Como a pulsão busca a realização e, como sabemos por Freud, atua nesta interface do psíquico-somático, penso que cada sujeito tem para si possibilidades de expressão histéricas, obsessivas, hipocondríacas, fóbicas, melancólicas, perversas, psicóticas... e psicossomáticas. O que privilegia esta ou aquela via de expressão do sujeito?

Seguramente que os investimentos narcísicos de objetos oriundos do desejo inconsciente do outro sobre a criança, em sua história pré e pós-natal, favorecendo uma ou outra via constitutiva são importantes, mas penso que é inerente à pulsão a busca da satisfação, e o aparelho psicossomático está aberto para realizá-la mesmo sob a pena de um superego tirânico e de um imperativo categórico destrutivo e gozador.

Estas idéias me reaproximam daquelas propostas por Groddeck, contemporâneo de Freud. Para ele o Isso, formador do corpo e da mente poderia utilizar-se de qualquer destas vias, psíquica ou somática para realizar os desejos inconscientes e proibidos pelo superego, porém não no sentido de uma histerização do corpo, como aponta Sami-Ali, nem no sentido de reduzir o corpo às neuroses atuais, conforme Reich?

Acredito que o conteúdo histórico ou os núcleos patógenos, ligados às experiências traumáticas recalcadas ou foracluídas, são determinantes para que um estímulo ou uma experiência atual possa ter efeito psicopatológico, num sentido retroativo realizador de desejos inconscientes e infantis.

Vários casos da clínica têm sugerido um intercâmbio dinâmico entre as chamadas estruturas clínicas que eu preferiria chamar manifestações clínicas psicopatológicas do aparelho psicossomático. Estas podem produzir efeitos desde um pólo predominantemente psíquico, cuja expressão poderia ser, por exemplo, a psicose ou a obsessão, até um pólo de expressão predominantemente somático,

5. S. Freud. "A pulsão e seus destinos". E.S.B. Rio de Janeiro, Imago.

6. S. Freud. "Projeto para uma psicologia científica". E.S.B. Rio de Janeiro, Imago.

7. Sami-Ali. Pensar o somático: imaginário e patologia. São Paulo, Casa do Psicólogo, 1995. 
como a lesão orgânica tecidual, como um tumor silencioso no fígado, passando por uma vasta gama de manifestações de conformidade mais ou menos histéricas.

No entanto, não consigo imaginar um caso sequer, onde o corpo pudesse estar dissociado da mente ou vice-versa. Mesmo um catatônico se implanta no corpo quando despertado pela fome ou pela dor. Seria um exercício para o pensamento imaginar uma situação humana onde o aparelho psicossomático não esteja presente em sua totalidade.

Groddeck, influenciado por Goethe e Nietzsche, admitia a existência de um Isso, como uma "entidade" quase espiritual, uma essência panteísta talvez, que preexistiria e de certa forma comandaria tanto a estruturação do corpo somático quanto do psíquico, e os utilizaria a "seu modo" para a realização de seus desejos, segundo os mesmos mecanismos propostos por Freud para o aparelho psíquico.

Podemos perceber isto em expressões suas como: "somos vividos pelo Isso"..." O Isso precede a formação do cérebro no período intra-uterino"... "Meu Isso queria..." (ver O livro d'Isso, 1923) ${ }^{8}$. Em sua atuação clínica com pacientes acometidos de doenças crônicas, dizia ser necessário "convencer" o Isso da possibilidade de outros caminhos para a realização do desejo que não pela via somática. Para tanto, aplicava as regras da psicanálise quanto à transferência, associação livre e à resistência.

Esta sua posição, um tanto mística, causou polêmicas no meio psicanalítico de sua época, relegando-o à margem tanto da psicanálise como da medicina. Só recentemente o valor de suas reflexões sobre a clínica da psicossomática vem sendo redescoberto.

Os psicossomatistas pós-groddeckianos, entre eles Ferenczi, Alexander, Dunbar, Balint, apesar de afirmarem a unidade psicossomática, passaram a desenvolver a idéia da psicogênese, ainda num modelo médico-mecanicista de causa-efeito.

Assim, um trauma psíquico ou uma sobrecarga psíquica de impossível ou insuficiente elaboração recai sobre o corpo. Por exemplo, uma derrocada econômica ou uma perda afetiva poderia ter como conseqüência a depressão, a culpabilidade, deprimindo o sistema imunológico e levando a pessoa a "contrair" uma tuberculose ou a produzir um câncer. $\mathrm{O}$ inverso também é válido: um trauma corporal intenso, proveniente do mundo interior ou exterior, por exemplo, uma amputação traumática, uma infecção pelo vírus HIV, provocaria intensa agressão ou estresse psíquico, depressão, suicídio etc. Nestes casos, cabe a indagação sobre o que é exterior e o que interior. Chegou-se a postular que determinados tipos psicológicos estariam mais predispostos a determinadas doenças cardiovasculares ou do aparelho digestivo etc.

8. G. Groddeck. O livro d'Isso. São Paulo, Perspectiva, 1991. 
$\begin{array}{lllllll}R & E & V & \text { I } & S & T & A\end{array}$

LATINOAMERICANA

DE PSICOPATOLOGIA

F U N D M N T A L

A partir dos anos sessenta, as contribuições da lingüística, da física quântica e da teoria do caos, vêm contestar toda a concepção linear e mecanicista do pensamento e dos fenômenos. Os efeitos multiplicativos de estímulos insignificantes e as respostas imprevisíveis passam a ser mais relevantes que as respostas lineares e previsíveis. ${ }^{9}$

A psicanálise é profícua em exemplos neste sentido. Quando retomamos o "a posteriori” dos efeitos da análise, não temos idéia de qual efeito transferencial propiciou esta ou aquela modificação psicossomática, se uma intervenção, uma não-intervenção, um chiste analítico, um corte na sessão...

Gostaria de tomar um exemplo clínico para pensar na versatilidade do sujeito humano em sua constituição psicossomática, considerar que sua "escolha" no sentido do sintoma pode ser a melhor possível para aquele momento, embora nem sempre uma "boa" opção.

Paciente: Ercília (nome fictício) ${ }^{10}$

O quadro sintomático é marcado por uma sensação de sufocamento no pescoço e um bócio tireoideano que passa a desenvolver-se após uma seqüência de perdas familiares, num período de meses: o pai, por morte súbita, a irmã diabética, mas em condições também inesperadas, e um filho num parto prematuro de seis meses, desencadeado a partir da notícia do falecimento da irmã.

As condições do atendimento deste filho prematuro abriram para Ercília um quadro delirante e, ao mesmo tempo, somático.

$\mathrm{O}$ recém-nato, segundo o obstetra, sem perspectiva de vida, foi colocado ao lado da mãe, ainda umbelicado (envolvido nas membranas amnióticas) e em respiração agônica. Ercília assim relata este momento de extrema angústia: "...aquele bebezinho sufocando, as costelinhas se moviam em desespero... eu deitada com a cabeça baixa e sem poder me mover... passei a sentir a mesma falta de ar... o mesmo sufocamento..."

A partir deste dia, Ercília se recolhe à casa, não dirige mais o automóvel, obtém licença médica para o trabalho. Passa a viver sob um sistema delirante, onde acredita que seus filhos (quatro, entre 8 e 14 anos), vão morrer sufocados. À noite, levanta-se várias vezes para ver se respiram... não consegue mais sair às ruas, pois os carros parecem vir ao seu encontro e é impossível para ela, que sempre adorou crianças, pegar um bebê ao colo ou dar a mão a uma criança

9. J. Gleick. Caos, a criação de uma nova ciência. Rio de Janeiro, Campus, 1990.

10. M. L. Souza. "A propósito de um caso de tireoidite (tire-o-dito)". Laboratório de Psicopatologia Fundamental, PUC-SP, 1996. 
para atravessar a rua, pois tem a convicção de que irão cair de suas mãos e morrer.

Paralelamente, seu pescoço torna-se progressivamente volumoso, uma "tireoidite" se instala, com gânglios dolorosos no pescoço e um cisto tireoideano. Seu olhar é brilhante, mas parece, para mim, dirigir-se para seu passado longínquo.

Ercília manifesta as seguintes percepções sobre seu pescoço: “...isto aqui me sufoca... tenho vontade de pegar uma faca e arrancar... sei que toda a minha doença está nisto aqui que me sufoca..."

Como bem observou Lacan, as associações livres interrompiam-se quando se tratava do "isto aqui no meu pescoço", muito embora a paciente apresentar uma facilidade em contar sua história e relembrar com detalhes fatos de sua infância, como ter presenciado um bebê se afogar com a própria mamadeira.

No início dos atendimentos, influenciado pelos a priori do simbolismo groddeckiano e culturais, dirigi minha escuta e até minhas intervenções no sentido de despertar Ercília do sonho em que permanecia adormecida e que me parecia estar relacionado à gestação interrompida. Posteriormente, percebi que esta era apenas uma "camada de sua cebola" histórica.

Vale dizer que esta paciente trazia uma riqueza de sintomas que não deixava nada a dever para Anna O. Vários deles foram cedendo à medida que as sessões transcorriam. Havia um peso nos braços, sobretudo o direito, e adormecimento nas mãos, que desapareceram à medida que a culpabilidade em relação ao parto prematuro e ao direito de ser mãe foram trabalhados. O sufocamento e os conteúdos delirantes se dissiparam com a progressão do tratamento.

Para mim, dois momentos transferenciais parecem ter sido importantes:

Um sonho, onde Ercília se vê em estado adiantado de gravidez, num quarto pronto para receber seu filho. Uma voz lhe dizia para ir ao Hospital, pois estava na hora do parto, mas havia angústia e ela dizia no sonho... "eu não sei porque não ia ao hospital, não saía do lugar..." A impressão que senti, talvez no meu imaginário, é de que Ercília teria vindo terminar o parto inacabado na transferência médico-psicanalítica.

Outro momento interessante foi quando "caroços" passaram a aparecer no abdome e no pescoço. Eram acúmulos de gordura, conhecidos no jargão médico como "lipomas". Mas para Ercília adquiriam um caráter altamente investido. Perguntava-se e me perguntava o que eram, o que significavam. Um ato falho veio lhe revelar nesta fala: "por que estão nascendo em mim estes caroços?..." Ao se dar conta deste "nascer", denegou: “... O senhor não vai me dizer que isto aqui é gravidez!..."; e ainda bem no momento em que interrompia a sessão:... “...sonhei a semana inteira que estava grávida...". A partir de então, deixou de se preocupar com os nódulos e eles foram desaparecendo. 
$\begin{array}{lllllll}R & E & V & \text { I } & \text { S } & T & A\end{array}$

LATINOAMERICANA

DE PSICOPATOLOGIA

FUND A M EN T A L

Qualquer psicanalista, lendo este relato de caso poderia dizer tratar-se de uma paciente com estrutura de uma neurose histérica com conteúdos delirantes. Mas tenho dificuldades em estabelecer limites estruturais em termos de funcionamento psíquico para ela.

Ercília extrapola os limites habitualmente considerados dentro das estruturas e transita "livremente" entre elas. Um dia comparece à sessão com o dedo ferido. Conta que o adormecimento nas mãos e dedos lhe impedia de trabalhar e alguma coisa lhe dizia para colocar o dedo no liqüidificador, que precisava feri-lo para melhorar o formigamento. Resistia à idéia de bater a cabeça ou pular de um lugar alto com a cabeça para baixo, para passar a dor de cabeça ou a tontura.

A evolução da análise pôde trazer à tona uma questão mais profunda do gozo no qual Ercília se mantém: ela traz uma sequiência de sonhos, onde se encontra na casa da infância, quer sair, mas há sempre alguém, um homem, que a obriga a voltar. Acorda tomada de muita angústia sempre que o sonho se repete. Num outro, está à beira de um lago, recolhendo uma moça vestida de branco, afogada, e a mesma voz lhe diz para deixá-la ali mesmo...

No material associativo destes sonhos, surge o cenário da infância, a casa, o lago, depois de muita resistência, reconhece neste homem o pai, temido e amado; o noivado com o homem que amou, a quem teve de renunciar, por ser pobre e o pai não permitiu o casamento. Seis meses após, namorou e casou-se com o atual marido, sem amá-lo, para sair de casa. Tentativa malograda, é infeliz no casamento com um homem que lhe é infiel, mas diz não ser capaz de romper o matrimônio, pois o pai não permitiria, sente que transferiu a obediência para o marido.

Passa a rememorar o quanto era absolutamente fiel ao pai e à mãe, não ousando contrariá-los em nada, obedecendo cegamente a tudo o que fosse mandado. Entre os irmãos sentia-se a menos amada, então não perdia oportunidades de agradar aos pais.

O pai era muito severo, e havia um castigo que lhe era particularmente desesperador: quando fazia algo "errado", o pai tinha por hábito pegá-la pelo pescoço com uma mão e suspendê-la junto à parede por algum tempo. Ao relatar este momento do castigo, em meio a tanta angústia, o desejo se revela capturado nesta vivência de gozo masoquista, (mas é quista) revelado nesta fala: “ ...e não sei porque eu não conseguia fazer as coisas certas, enquanto os meus irmãos sabiam escapar deste castigo mais facilmente..."

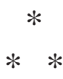

Acho interessante pensar os sintomas somáticos como um modo de funcionamento de um sistema complexo e dinâmico que podemos chamar psicossoma ou aparelho psicossomático. Este sistema me parece existir numa 


\section{ARTIGOS}

relação diferente da de causa-efeito com o sintoma, ou como um aparelho simbolizante, com maior ou menor capacidade de elaborar impressões psíquicas, sensoriais ou afetivas.

Outra idéia que me tem surgido, a partir da observação clínica, é de que as "saídas" somáticas podem ocorrer, de maneira totalmente inconsciente, como mecanismos de curas psíquicas, sem que o aparelho simbolizante tenha notícia, pelo menos em primeira instância.

É o caso de um paciente que acompanho, com um câncer de pulmão, que surge como evolução de um quadro depressivo de vários anos; é como se a doença física materializasse o objeto melancólico. As reações exacerbadas à quimioterapia pareciam traduzir o desejo de não se tratar. Um dia sou chamado às pressas pela família, para atendê-lo num quadro que se caracterizou por um acidente vascular cerebral. Alguns dias de internação, afasia para expressar-se (incapacidade de encontrar as palavras para traduzir os pensamentos), e uma pequena sequiela motora à direita; mas acabou recuperando-se. Porém algo aconteceu, inexplicável para mim e notado imediatamente pela esposa. Já no dia seguinte ao acidente cerebral, o paciente sorria, fazia piada com o seu estado; seu estado de humor modificou-se completamente, passando a colaborar com o tratamento quimioterápico, apresentando reações muito mais toleráveis, o que resultou no desaparecimento das lesões cancerosas, entrando atualmente num estado mais favorável de remissão de sua doença. Qual doença? Digo a ele que precisou de um curto-circuito cerebral para tomar outro rumo na vida.

O sintoma, seja ele de expressão psíquica ou somática pode relacionar-se com a busca inconsciente, pois que inerente à pulsão, da realização dos desejos infantis edípicos e pré-edípicos, desde a nostalgia da unificação onipotente e porque não dizer fálica com a mãe, ao mesmo tempo que amorosa e protetora, mortífera e devoradora, passando pelos amores incestuosos vivenciados inconscientemente no complexo de Édipo.

Esta posição torna o sujeito muito mais agente e responsável por seus infortúnios do que simplesmente passivo ou produto da sorte. Evoca também a idéia de castração num sentido de grau de entrada do sujeito à submissão simbólica da função paterna (Lacan), neste binômio mãe-bebê, e como consequiência, qual o lugar que o sujeito ocupa nestes dois pólos representados, de um lado, pelo mergulho na mãe, que seria a pulsão de morte ou a morte psíquica e, de outro, a constituição de um sujeito desejante, pois que aceita a impossibilidade desta indiferenciação e submete-se ao universo dos falantes e castrados, tendo para sua pulsão, encaminhamentos de ordem sublimatória. 


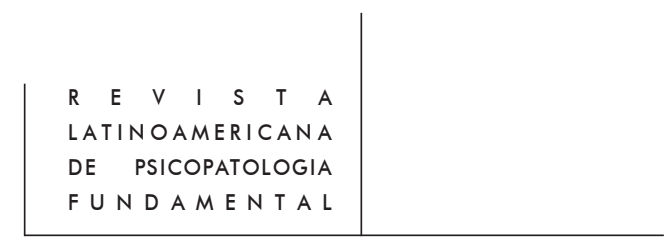

\section{Resumos}

Partiendo de la experiencia de atendimiento a pacientes acometidos de patologias somáticas, el autor ensaya algunas elaboraciones acerca de los conceptos de estructuras psíquicas en psicanálise en relación a las manifestaciones psicosomáticas. En un intento de abordar la complejidad de la unidad bio-psico-física que constituye el ser humano, el autor propone los términos "psicosoma" o "aparato psicosomático" en oposición al término "aparato psíquico".

Based on the experience of treating patients manifesting somatic disorders, the author brings forth some elaborations concerning the concept of psychic structures in psychoanalysis related to psychosomatic disorders.

In an attempt to elucidate the complexity of the bio-psycho-physical unity which constitutes human beings, the author proposes the terms "psychosoma" or "psychosomatic apparatus" as substitutes for the term "psychic apparatus". 